\title{
Willingness to pay for social health insurance and its determinants among public servants in Mekelle City, Northern Ethiopia: a mixed methods study
}

\author{
Meles Tekie Gidey ${ }^{1}$, Gebremedhin Beedemariam Gebretekle ${ }^{2}$, Mary-Ellen Hogan ${ }^{3}$ and Teferi Gedif Fenta $2^{2 *}$
}

\begin{abstract}
Background: Owing to lack of adequate healthcare financing, access to at least the basic health services is still a problem in Ethiopia. With the intention of raising funds and ensuring universal health coverage, a mandatory health insurance scheme has been introduced. The Community Based Health Insurance has been implemented in all regions of the country, while implementation of social health insurance was delayed mainly due to resistance from public servants. This study was, therefore, aimed to assess willingness to pay for social health insurance and its determinant factors among public servants in Mekelle city, Northern Ethiopia.

Methods: A concurrent mixed approach of cross-sectional study design using double bound dichotomous choice contingent valuation method and qualitative focus group discussions was employed. A total 384 public servants were recruited from randomly selected institutions and six focus group discussions $(n=36)$ were carried out with purposively selected respondents. Participants' mean willingness to pay (WTP) and independent predictors of WTP were identified using an interval data logit model. Qualitative data were analyzed using thematic analysis.

Results: From the 384 participants, 381 completed the interview, making a response rate of $99.2 \%$. Among these respondents $85.3 \%$ preferred social health insurance and were willing to pay for the scheme. Their estimated mean WTP was 3.6\% of their monthly salary. Lack of money to pay (42.6\%) was the major stumbling block to enrolling in the scheme. Respondents'WTP was significantly positively associated with their level of income but their WTP decreased with increasing age and educational status. On the other hand, a majority of focus group discussion participants were not willing to pay the $3 \%$ premium set by the government unless some preconditions were satisfied. The amount of premium contribution, benefit package and poor quality of health service were the major factors affecting their WTP.

Conclusion: The majority of the public servants were willing to be part of the social health insurance scheme, with a mean WTP of $3.6 \%$ of their monthly salary. This was greater than the premium proposed by the government (3\%). This can pave the way to start the scheme but attention should focus on improving the quality of health services.
\end{abstract}

Keywords: Willingness to pay, Health insurance, Contingent valuation method, Universal health coverage, Ethiopia

\section{Background}

Significant proportions of people all over the world suffer and die due to lack of access to basic healthcare

\footnotetext{
*Correspondence: tgedif@gmail.com

${ }^{2}$ School of Pharmacy, College of Health Sciences, Addis Ababa University, Addis Ababa, Ethiopia

Full list of author information is available at the end of the article
}

services. In low and middle-income countries alone, 150 million people suffer a health-related financial catastrophe each year, and 100 million people (the equivalent of three people every second) are pushed into poverty as a result of out of pocket (OOP) health expenditures [1-3]. OOP health expenditure is the major source of health care financing in low income countries and those with emerging economies compared to developed nations. 
Individuals in countries with emerging economies paid $75.1 \%$ to $97.7 \%$ of their private healthcare expenditures [4]. In addition, the coverage of health services in these countries is constrained by inadequate funding $[5,6]$. High reliance on OOP payment and high dependency on funding from development assistance are the main reason for lack of funding for health in low and middle income countries [7].

This indicates that health service fees are a major obstacle to healthcare coverage and utilization [8], and the only way to reduce reliance on direct OOP payments and to attain Universal Health Coverage (UHC) for governments is to encourage the risk-pooling prepayment mechanisms $[9,11]$. In 2005, WHO urged member states to "ensure that health-financing systems introduce or develop prepayment of financial contributions for the health sector, with a view to sharing risk among the population and avoiding catastrophic healthcare expenditure and impoverishment of individuals as a result of seeking care" [10]. In connection with this, many low and middle income countries are considering on how to reform their health care systems to provide effective financial risk protection for all, as part of UHC [1,3]. Introducing Social Health Insurance (SHI) was considered as one of the most powerful risk pooling mechanisms in most developing countries to achieve UHC. The UHC had been achieved in many countries in the world by establishing SHI as the country's health care financing mechanism [11].

Like many other low income countries, healthcare financing has been a major challenge for Ethiopians. Government expenditure on health as a percentage of total expenditure was $5.4 \%$ which is below the targets set by Abuja Declaration of 15\% [12] and $90.6 \%$ of the total health expenditure is funded from household OOP expenditures [13]. Per capita annual national health expenditure was US\$21 in 2010/11 which was far below the WHO recommendation of US\$44 per capita for lowincome countries [14]. The national health expenditure is expected to reach US\$212 in 2040, with government spending $4.6 \%$ of GDP, which will be still lower than the expected average spending of lower income countries (6.7\%) [8].

As a result of financial constraints for health, the Ethiopian Federal Ministry of Health began health care financing reform in 1998 to improve and diversify resource mobilization for health and secure financial protection for its citizens. Implementing a health insurance scheme was one of nine intervention strategies mentioned in this reform [15]. The government developed a health insurance strategy in 2008, and two types of health insurance have been proposed since 2010, Community Based
Health Insurance and Social Health Insurance (SHI) [16, 17].

The Community Based Health Insurance scheme was intended to cover approximately $89 \%$ of the population who are mainly rural dwellers. The SHI was intended to cover the employed and their family members, approximately $11 \%$ of the population (public servants, permanent employees working in private organizations and pensioners). Enrollment in SHI is compulsory and the proposed contribution is $3 \%$ of their salary [17]. The insurance benefit package includes outpatient care, inpatient care, delivery services, surgical service, diagnostic tests and generic drugs included in the drug list of the health insurance agency. Treatment outside Ethiopia, treatment related to drug abuse or addiction, periodic medical checkups unrelated to illness, cosmetic surgery, dentures, implants, crowns, organ transplants, dialysis except acute renal failure, provision of eye glasses, contact lenses and hearing aids are excluded from the benefit packages [18].

Despite the government's plan to fully implement SHI by 2014 [19], it has been repeatedly postponed, largely due to strong resistance from public servants. Hence, this study was conducted to explore public servants' WTP and factors contributing to resistance to SHI. The study focused on health professionals, teachers and support staff employed in health facilities and schools. Understanding the views of teachers and health professionals is important because of their influence in the society which could be either positive or negative. Support staffs were also enrolled in the study to gain information about the perspectives of the relatively lower income segments of the public servants on SHI.

\section{Methods}

The study employed a mixed methods approach using a contingent valuation study and a qualitative study using focus group discussions (FGDs). The study was conducted in Mekelle City, Tigray Regional State, Northern Ethiopia between April and May, 2017. Respondents were recruited from schools and health facilities. Employees must have worked for at least 6 months and be willing to participate in the study.

A sample size of 384 was calculated for the crosssectional survey using a single population proportion formula [19]; assuming 50\% of the public servants are willing to pay with $95 \% \mathrm{CI}$ and $5 \%$ margin of error. A proportional number of respondents were drawn from each institution (four high schools, eight elementary schools, two hospitals, and five health centers) which were selected using systematic random sample technique. An interviewer-administered structured questionnaire was adapted from other studies [19-21] and pretested 
among 29 public servants prior to the actual data collection and modification was done accordingly (Additional file 1). The questionnaire included participants' sociodemographics, healthcare utilization and hypothetical healthcare financing scenarios to determine their WTP. The English version questionnaire was translated into local language (Tigrigna) and back translated into English for consistency. Data were collected by three trained pharmacists.

Following the quantitative survey, six FGDs (6 discussants each, $n=36$ ) were carried out to obtain information regarding participants' perceived affordability of healthcare costs, knowledge and understanding of health insurance, WTP for SHI and concerns about SHI implementation. The FGD participants were comprised of two FGDs with teachers, two with health professionals and two with support staff. The head of each institution was consulted in choosing the FGD participants. The discussants did not participate in the quantitative survey. The first author (MTG) and trained research assistant facilitated all FGDs using a semi-structured interview guide with flexible probing techniques (Additional files 2 and 3). All discussions were tape recorded and transcribed verbatim. Each FGD lasted 45 to $80 \mathrm{~min}$ with a mean of $55 \mathrm{~min}$.

\section{Choice of WTP method}

The double bound dichotomous choice (DBDC) approach was used to estimate the WTP as it has good statistical efficiency and is simple to conduct, and it has been extensively used in the valuation of non-marketed goods [22]. In contingent valuation, first the hypothetical market is described to respondents and a series of questions was asked. Three hypothetical scenario choice sets were adapted from previous studies in Ethiopia [20, 23]. The set of choices were scenario A, which was no insurance; scenario B- compulsory insurance (social health insurance); scenario $\mathrm{C}$-voluntary insurance (Additional file 1). In this method, the respondent only answers 'yes' or 'no' to a given question about the WTP amount [24]. Different starting bids identified from the pretest (i.e. 2, 3, 4 and 6\%) were distributed randomly to participants and the respondent was asked whether he/she was willing to pay for a specified bid amount. If the respondent says 'yes' to the first bid, a second bid that was twice as much would be offered. If the respondent says "No" to the first bid, a second lower bid (1/2 first bid) would be offered. The first bid amount was distributed to the respondents randomly to minimize starting point bias.

Assuming a linear functional form for the WTP, the econometric model is:

$$
\operatorname{WTP}_{\mathrm{i}}\left(\mathrm{z}_{\mathrm{i}}, \mathrm{u}_{\mathrm{i}}\right)=\mathrm{z}_{\mathrm{i}} \beta+\mathrm{u}_{\mathrm{i}}
$$

where $z_{i}$ is a vector of explanatory variables, $\beta$ is a vector of parameters and $u_{i}$ is an error term assumed to be independently and randomly distributed with mean zero and constant variance, $\sigma^{2}$.

Let the first bid amount be $t_{1}$ and the second one $t_{2}$, and then each individual will be in one of the following categories:

1. The individual answers 'yes' to the first question and 'no' to the second, then $t_{2}>t_{1}$. In this case we can infer that $t_{1} \leq \mathrm{WTP}<\mathrm{t}_{2}$.

2. The individual answers yes to the first question and yes to the second, then $t_{2} \leq \mathrm{WTP}<\infty$.

3. The individual answers no to the first question and yes to the second, then $t_{2}<t_{1}$. In this case we have $\mathrm{t}_{2} \leq \mathrm{WTP}<\mathrm{t}_{1}$.

4. The individual answers no to the first and second questions, then we have $0<\mathrm{WTP}<\mathrm{t}_{2}$.

Then, the probability of each of the four cases is defined as:

$$
\begin{aligned}
& \text { A. } \operatorname{Pr}\left(t_{1} \leq W T P<t_{2}\right) \\
& \quad=\operatorname{Pr}\left(\frac{t_{1}-z_{i}^{\prime} \beta}{\sigma} \leq \frac{u_{i}}{\sigma}<\frac{t_{2}-z_{i}^{\prime} \beta}{\sigma}\right) \\
& \quad=\Phi\left(z_{i}^{\prime} \frac{\beta}{\sigma}-\frac{t_{1}}{\sigma}\right)-\Phi\left(z_{i}^{\prime} \frac{\beta}{\sigma}-\frac{t_{2}}{\sigma}\right) \\
& \text { B. } \operatorname{Pr}\left(W T P>t_{1}, W T P>t_{2}\right)=\Phi\left(z_{i}^{\prime} \frac{\beta}{\sigma}-\frac{t_{2}}{\sigma}\right) \\
& \text { C. } \operatorname{Pr}\left(t_{2} \leq W T P<t_{1}\right)=\Phi\left(z_{i}^{\prime} \frac{\beta}{\sigma}-\frac{t_{2}}{\sigma}\right)-\Phi\left(z_{i}^{\prime} \frac{\beta}{\sigma}-\frac{t_{1}}{\sigma}\right) \\
& \text { D. } \operatorname{Pr}\left(W T P<t_{1}, W T P<t_{2}\right)=1-\Phi\left(z_{i}^{\prime} \frac{\beta}{\sigma}-\frac{t_{2}}{\sigma}\right)
\end{aligned}
$$

Estimation of $\beta$ and $\sigma$ was based on the maximum likelihood method. The function that needs to be maximized to find the parameters of the model is:

$$
\begin{aligned}
& \sum_{i=1}^{N}\left[d_{i}^{y n} \ln \left(\Phi\left(z_{i}^{\prime} \frac{\beta}{\sigma}-\frac{t_{1}}{\sigma}\right)-\Phi\left(z_{i}^{\prime} \frac{\beta}{\sigma}-\frac{t_{2}}{\sigma}\right)\right)\right. \\
& +d_{i}^{y y} \ln \left(\Phi\left(z_{i}^{\prime} \frac{\beta}{\sigma}-\frac{t_{2}}{\sigma}\right)\right) \\
& +d_{i}^{n y} \ln \left(\Phi\left(z_{i}^{\prime} \frac{\beta}{\sigma}-\frac{t_{2}}{\sigma}\right)-\Phi\left(z_{i}^{\prime} \frac{\beta}{\sigma}-\frac{t_{1}}{\sigma}\right)\right) \\
& \left.+d_{i}^{n n} \ln \left(1-\Phi\left(z_{i}^{\prime} \frac{\beta}{\sigma}-\frac{t_{2}}{\sigma}\right)\right)\right]
\end{aligned}
$$


where $d_{i}^{y n}, d_{i}^{y y}, d_{i}^{n y}, d_{i}^{n n}$ are indicator variables that take the value of one or zero depending on the relevant case for each individual. Each respondent contributes to the logarithm of the likelihood function in only one of its four parts. Hence, we obtain directly $\beta$ and $\sigma$ then we can estimate WTP [25].

\section{Data analysis}

The quantitative data were analyzed using Stata version 12.0. Participants' socio-demographic characteristics, household members' chronic disease status, their occupation, presence of free health coverage and prior information on health insurance were the factors assessed for predicting WTP. Their mean WTP and predictors of WTP were identified using the interval data logit model using the 'doubleb' command in Stata 12 as explained by Lopez-Feldman [25]. The significance level was set at $95 \%$ confidence interval and $p$-value $<.05$. The qualitative data was manually analyzed employing thematic analysis. Authors MTG and GBG in collaboration with authors TGF and MEH carried out the analysis and interpretation of the data. Finally, findings were shared with six of the participants (one each from the FGDs) and they confirmed that the interpretations were reflective of their insight and experiences (Additional file 4).

\section{Results}

\section{Socio-demographic characteristics of the study participants}

From the 384 participants, 381 participated in the interview, making a response rate of $99.2 \%$. The majority $(60.1 \%)$ of participants was females and their mean $( \pm S D)$ age was $37( \pm 9.2)$ years. The average family size and monthly household income of participants was $3.4( \pm 1.8)$ and 5423 $( \pm 3165)$ Ethiopia Birr (ETB) (1US\$ =23ETB), respectively. A summary of socio-demographic characteristics is presented in Table 1.

\section{Health and health care related characteristics of the study participants}

One hundred and sixty (42.0\%) respondents had at least one episode of acute illness in the last 12 months and almost all $(98.1 \%)$ of them sought treatment for their recent episodes. Of the total participants, $282(74.0 \%)$ of respondents' healthcare expenditure was OOP and 306 $(80.3 \%)$ of them reported that it was unaffordable. At the same time, about half $(51.7 \%)$ of respondents were not satisfied with the quality of health services being rendered in public health facilities (Table 2).

Respondents' preference for health care financing options The majority 336 (88.2\%) of respondents agreed on the need to introduce SHI. Regarding their preference of
Table 1 Socio-demographic characteristics of public servants in Mekelle City, Northern Ethiopia, 2017

\begin{tabular}{|c|c|c|c|c|}
\hline \multirow[t]{2}{*}{ Variables } & \multicolumn{2}{|c|}{ Survey participants } & \multicolumn{2}{|c|}{$\begin{array}{l}\text { Focus group } \\
\text { participants }\end{array}$} \\
\hline & Frequency & Percentage & Frequency & Percent \\
\hline \multicolumn{5}{|l|}{ Gender } \\
\hline Male & 152 & 39.9 & 21 & 58.3 \\
\hline Female & 229 & 60.1 & 15 & 41.7 \\
\hline \multicolumn{5}{|l|}{ Age category } \\
\hline$<30$ & 91 & 23.9 & 11 & 30.6 \\
\hline $30-39$ & 146 & 38.3 & 12 & 33.3 \\
\hline$>40$ & 144 & 37.8 & 13 & 36.1 \\
\hline \multicolumn{5}{|l|}{ Marital status } \\
\hline Not married & 147 & 38.6 & 13 & 36.1 \\
\hline Married & 234 & 61.4 & 23 & 63.9 \\
\hline \multicolumn{5}{|c|}{ Respondents educational status } \\
\hline Elementary school & 23 & 6.0 & & \\
\hline Diploma certificate & 153 & 42.5 & 19 & 52.8 \\
\hline Degree and above & 196 & 51.5 & 17 & 47.2 \\
\hline \multicolumn{5}{|l|}{ Occupation } \\
\hline Teacher & 171 & 44.9 & 12 & 33.3 \\
\hline Health professional & 125 & 32.8 & 12 & 33.3 \\
\hline Supportive staff & 85 & 22.3 & 12 & 33.3 \\
\hline \multicolumn{5}{|l|}{ Household family size } \\
\hline$\leq 3$ & 186 & 48.8 & 17 & 47.2 \\
\hline $4-6$ & 178 & 46.7 & 14 & 38.9 \\
\hline$\geq 7$ & 17 & 4.5 & 5 & 13.9 \\
\hline \multicolumn{5}{|c|}{ Homes with children under age 5 years } \\
\hline No & 257 & 67.5 & 21 & 58.3 \\
\hline Yes & 124 & 32.5 & 15 & 41.7 \\
\hline
\end{tabular}

health care financing, 325 (85.3\%) of them preferred the mandatory SHI package; while 11 (2.9\%) of them preferred voluntary health insurance. In general, 336 (88.2\%) of the respondents were supportive of introducing a health insurance scheme, either voluntary or mandatory. However, 45 (11.8\%) participants preferred OOP health expenditure (Additional file 4).

Respondents' willingness to pay for social health insurance Regarding the initial bid distribution, 77 (23.69\%), 82 (25.2\%), $80(24.6 \%)$ and $86(26.4 \%)$ of the participants picked 2, 3, 4 and $6 \%$ initial bid amounts, respectively. About $48.6 \%$ of them responded "yes" to the first bid (Fig. 1).

Across the contingent valuation question, the amount of first bid was an important factor behind participants WTP. As the bid amount increased, the probability of acceptance decreased (Fig. 2). 
Table 2 Health and health related situations among public servants in Mekelle City, Northern Ethiopia, 2017

\begin{tabular}{|c|c|c|}
\hline Description & Frequency & Percent \\
\hline \multicolumn{3}{|c|}{ Presence of chronic illness among family members $(n=381)$} \\
\hline Yes & 71 & 18.6 \\
\hline \multicolumn{3}{|c|}{ Presence of acute illness in a family member in 12 months period $(n=302)^{\text {a }}$} \\
\hline Yes & 136 & 45.0 \\
\hline \multicolumn{3}{|c|}{$\begin{array}{l}\text { Presence of any acute illness on the respondent within } 12 \text { months period } \\
(n=381)\end{array}$} \\
\hline Yes & 160 & 42.0 \\
\hline \multicolumn{3}{|c|}{ Seeking treatment for the recent episode of illness $(n=160)$} \\
\hline Yes & 157 & 98.1 \\
\hline \multicolumn{3}{|c|}{ Place of treatment sought $(n=157)$} \\
\hline Private health facility & 25 & 15.9 \\
\hline Public health facility & 132 & 84.1 \\
\hline \multicolumn{3}{|c|}{ Healthcare expenditure $(n=381)$} \\
\hline Out of pocket & 282 & 74.0 \\
\hline Employer & 67 & 17.5 \\
\hline Others (free, civic society) & 33 & 8.5 \\
\hline \multicolumn{3}{|c|}{ Affordability of health care costs $(n=381)$} \\
\hline Affordable & 75 & 19.7 \\
\hline Not affordable & 306 & 80.3 \\
\hline \multicolumn{3}{|c|}{ Satisfaction with quality of services at public health facilities $(n=381)$} \\
\hline Dissatisfied & 197 & 51.7 \\
\hline Neutral & 37 & 9.8 \\
\hline Satisfied & 147 & 38.6 \\
\hline \multicolumn{3}{|c|}{ Satisfaction with the cost of services at public health facilities $(n=381)$} \\
\hline Dissatisfied & 120 & 31.5 \\
\hline Neutral & 27 & 7.1 \\
\hline Satisfied & 234 & 61.4 \\
\hline
\end{tabular}

${ }^{a}$ Questions were not answered by all participants

The large majority (85.3\%) of public servants were willing to join and pay for SHI. The overall estimated mean WTP was 3.6\% (95\% CI 3.4-3.8) of their gross monthly salary. Access to free health services 277 (85.2\%), financial security in times of ill health 278 (85.5\%) and helping others who can't afford their medical bills 238 (73.2\%) were mentioned as the key drivers for their WTP. For those who were not willing to join 56 (14.7\%), lack of money to pay was raised as the main reason $23(41.1 \%)$ (Table 3).

Predictors of willingness to pay for social health insurance Respondents' WTP was significantly associated with their age, educational status and household income. In this regard, older age and more educated respondents were willing to pay less as compared to their younger counterparts. But, as respondents' household income increased, the amount they were willing to pay also increased. The result of the model is presented in Table 4.

\section{Qualitative findings}

A total of six FGDs were conducted and three major themes were emerged from the thematic analysis: affordability of health services, participants' knowledge of health insurance and factors influencing WTP for SHI.

\section{Affordability of health services}

For the majority of the participants, OOP payment was a means to cover their health expenditure but very few of them had employment-based healthcare coverage. All participants agreed that healthcare was expensive and as a result, significant numbers of participants failed to seek medical care on time, due to a shortage of money. They reported that they cannot afford their medical bills unless they borrow from relatives. This has been illustrated by one teacher:

"Healthcare costs are very expensive, unaffordable and I don't think they consider the income of most employees. Considering my income and affordability of health services, having a serious health problem is similar to death sentence (Male, 59 years, Teacher)".

On the other hand, some of the participants indicated that the cost of health services was fair in public health facilities compared to private ones, but the lack of some diagnostic tests, poor service quality and shortages of medications in the public system were major aggravating factors for extra expense and lack of access as compared to private hospitals. One support staff from a health institution stated that:

"The cost of medication is lower in public hospitals but there is a frequent shortage of vital medicines. When the private pharmacies know that a particular medicine is out of stock from public health facilities, they would immediately increase the price way too high. This forced us to pay an extra high cost, which is unaffordable to many public servants (Female, 27 years, Support staff)."

\section{Knowledge of health insurance}

The majority of participants had good knowledge regarding what health insurance is, how it works and its concepts and purpose. They viewed health insurance as crucial to access to healthcare for all citizens regardless of their socioeconomic status. Most participants believed that everyone can benefit from SHI but a few of them strongly argued that only the poor are beneficiaries of the scheme. This was illustrated by one participant:

"Health insurance is about helping each other in times of ill health based on prior contributions. Because none of us is certain about our health sta- 


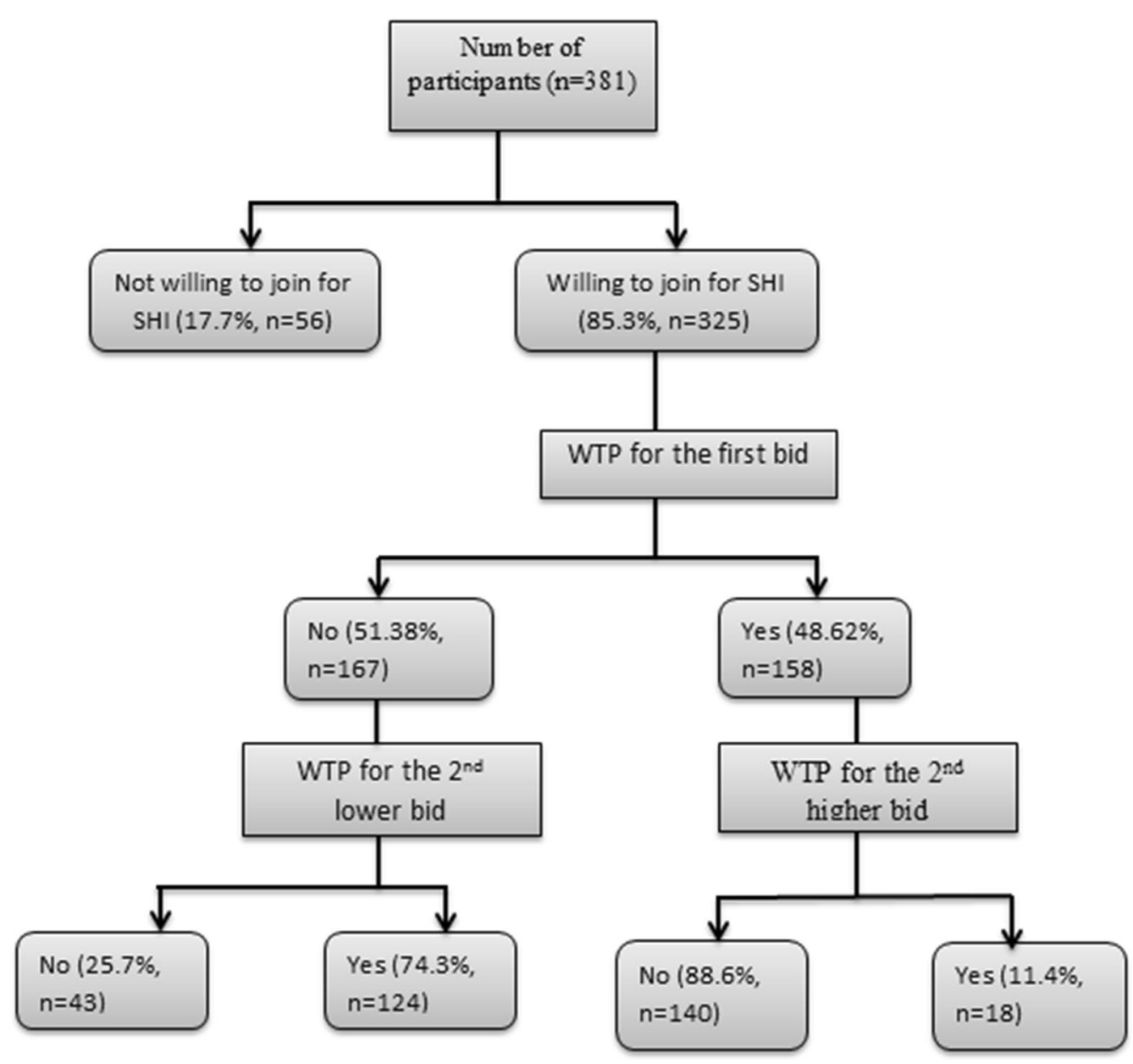

Fig. 1 Summary statistics to double-bounded dichotomous choice questions

tus, it is important to have a guarantee for everyone: all people whether rich or poor may not have money at hand in times of emergency health conditions. It is amazing that every car in Ethiopia has insurance but we don't have health insurance for our precious life (Male, 42 years, Health professional)".

\section{Factors influencing willingness to pay for social health insurance}

Once health expenditure and knowledge of health insurance was explored; the principle, purpose and benefit packages of SHI were explained. Perceived need and factors affecting participants' WTP were then discussed. Four sub-themes emerged: premium contribution; benefit package, quality of health services and eligibility of family members to be covered.

\section{Premium contribution}

We used a $3 \%$ premium contribution, the premium set by the Ethiopian Health Insurance Agency, to elicit participants' WTP. Despite their support to implement of SHI, a majority of the participants were not willing to contribute $3 \%$ of their gross monthly salary. The low salary, very high cost of living, and burden of other deductions from their salary were mentioned as the major reasons for the view. One participant stated that:

"With my current income, contributing 3\% is diffcult. Nowadays, everything is expensive and I have a lot of other expenses such as house rent, food, school fee... for my family. I should not suffer to pay for SHI. I believe if you don't wear clean cloths and eat right, you would get sick. It is unquestionable on the need to have SHI but the contribution should not lead us to further crisis and illness (Male, 60 years, Teacher)". 


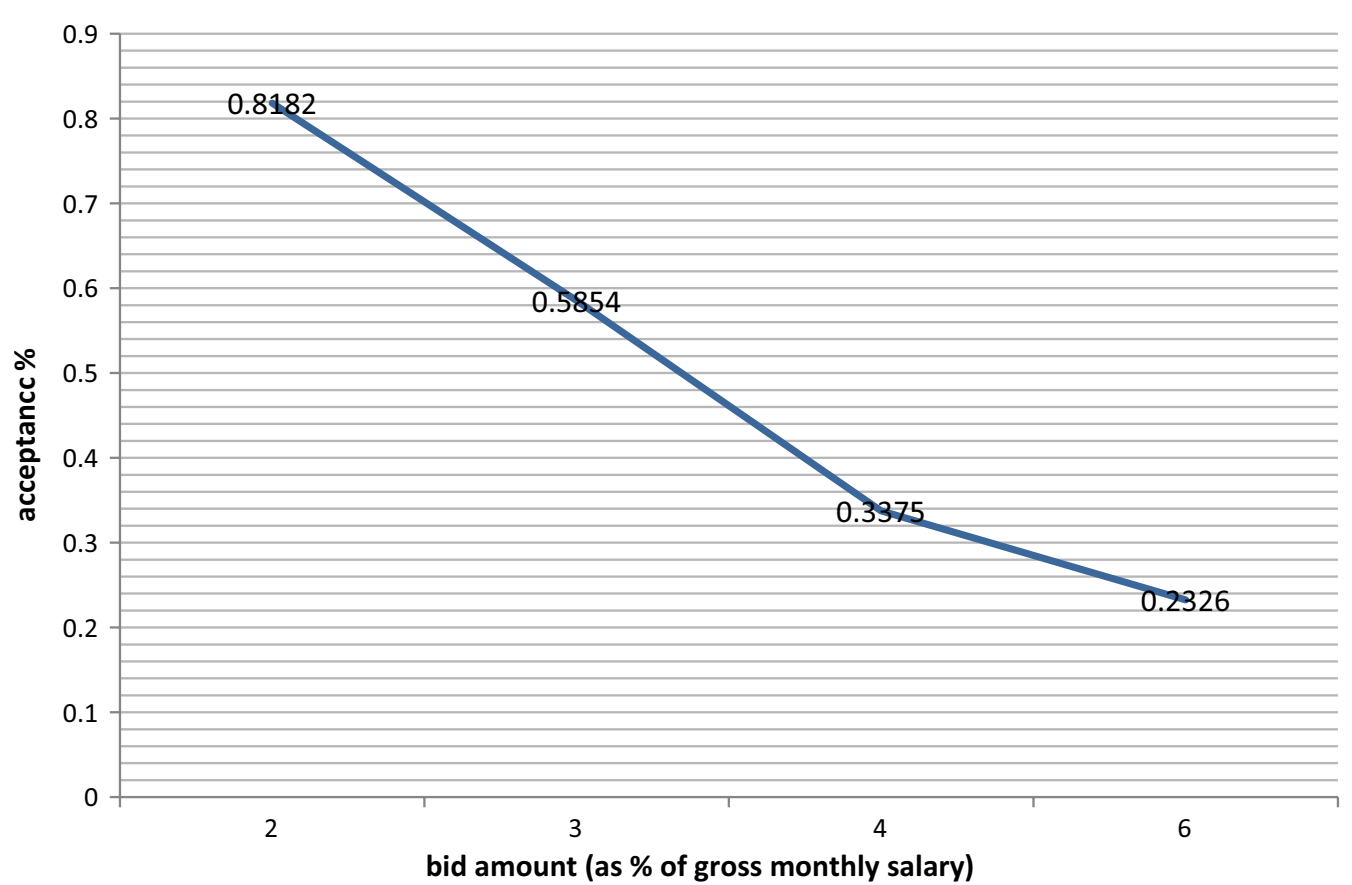

Fig. 2 Respondents bid acceptance rate (\%) and bids amounts (as \% of gross monthly salary) (using double bounded dichotomous choice method)

Table 3 Reasons behind public servants' willingness/ unwillingness to pay for social health insurance in Mekelle City, Northern Ethiopia, 2017

\begin{tabular}{|c|c|c|}
\hline Variable & Frequency & Percent \\
\hline \multicolumn{3}{|l|}{ Reasons for joining SHI $(n=325)^{\mathrm{a}}$} \\
\hline $\begin{array}{l}\text { To get free health service at point of service } \\
\text { provision }\end{array}$ & 277 & 85.2 \\
\hline $\begin{array}{l}\text { To help others who can't afford their medical } \\
\text { costs }\end{array}$ & 238 & 73.2 \\
\hline $\begin{array}{l}\text { For security and peace of mind in times of } \\
\text { ill-health }\end{array}$ & 278 & 85.5 \\
\hline Facing health problem frequently & 14 & 4.3 \\
\hline \multicolumn{3}{|l|}{ Reasons for not joining SHI $(n=56)^{\mathrm{a}}$} \\
\hline Lack of money to pay & 23 & 41.1 \\
\hline It doesn't cover all health services & 12 & 21.4 \\
\hline $\mathrm{OOP}$ charge is better & 12 & 21.4 \\
\hline Lack of trust in insurance scheme & 17 & 30.4 \\
\hline $\begin{array}{l}\text { Poor quality of health service in public health } \\
\text { facility }\end{array}$ & 9 & 16.1 \\
\hline $\begin{array}{l}\text { Others (double payment from wife and husband, } \\
\text { government should pay, I have free card) }\end{array}$ & 5 & 8.9 \\
\hline
\end{tabular}

${ }^{a}$ Multiple answers possible (total may exceed 100\%)

Considering this burden, most of the respondents argued that $2 \%$ is enough contribution for the listed benefit packages. But a few of them were willing to pay more if the benefit packages would be revised. On the other hand, about one-fourth of the participants was willing to pay the $3 \%$ contribution and argued that a lesser premium would be an obstacle to achieving universal health coverage. However, community engagement and continuous discussions were suggested before implementation. One health professional stated:

"If the contribution is too small, it is valueless as it can't cover even the basic health services, let alone costly medications and diagnoses. Hence, the program will finally fail to succeed in its objective which could have unprecedented repercussions to everyone involved (Male, 40 years, Teacher)".

Another participant stated that:

"I am willing to contribute 3\% but the problem is we don't know the benefits and most of the time the government obliges public servants to contribute in many development plans without our consent. This is not a good approach. I think having a clear and genuine discussion is important to solve these ambiguities (Male, 40 years, Teacher)".

A few of the health professionals claimed that they should not pay for services they provide, stressing that they are at high risk of infection or other harm and should therefore be entitled to get health services free of charge as compensation. One health professional argued that: 
Table 4 The effect of explanatory variables on public servants' willingness to pay for social health insurance in Mekelle City, Northern Ethiopia, 2017

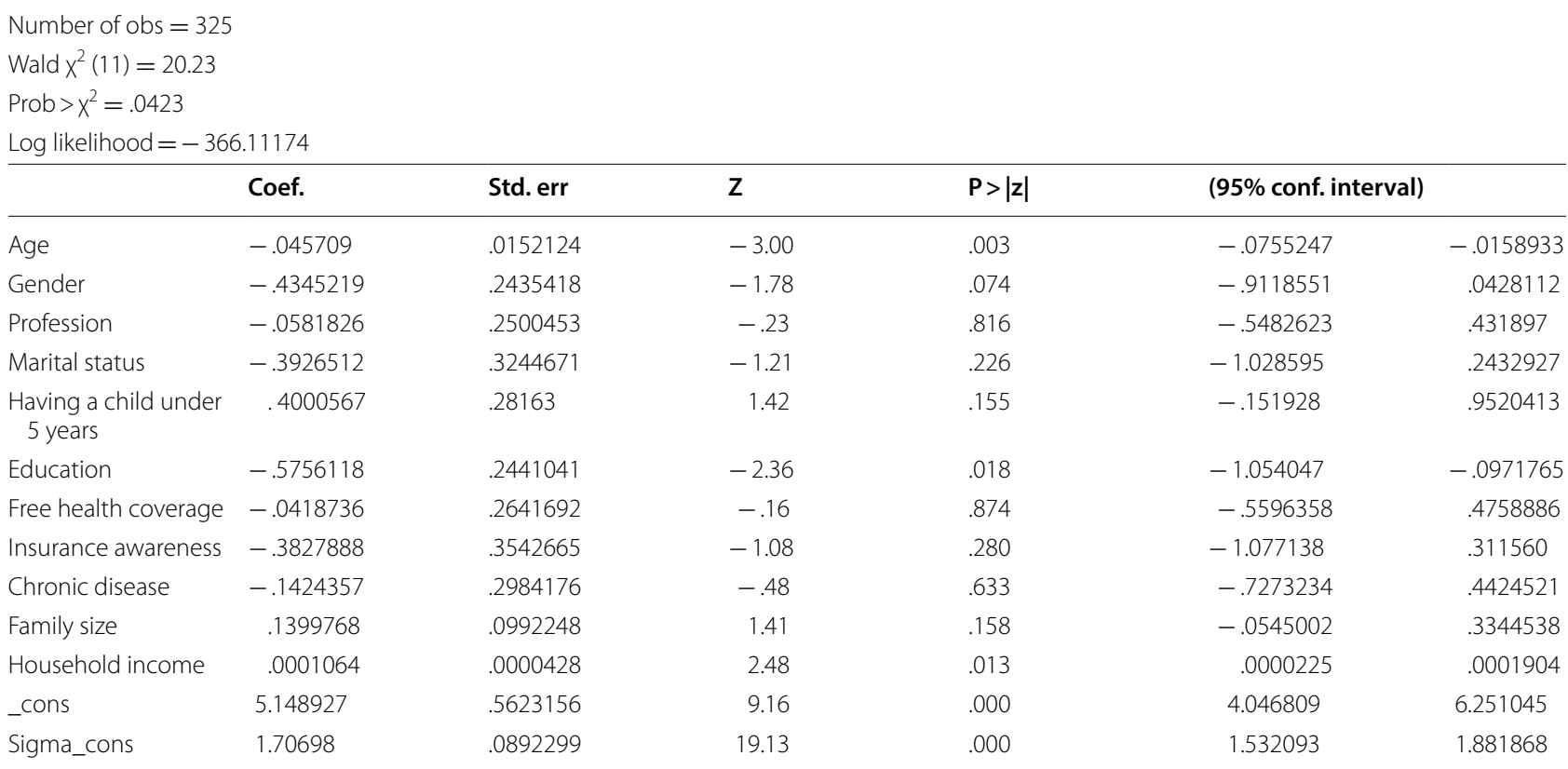

"I shouldn't contribute at all and it's unfair if the government wanted us to accept it. I don't. It is not fair to pay services that you can provide by yourself, as a health professional. Again, don't forget that we are working in a risky environment. So, not only should I be treated freely but I should also be paid a hazard allowance for the possible risks while treating my patients (Male, 36 years, Health professional)".

\section{Benefit packages}

More than $1 / 3$ rd of participants argued that the list benefits included in the package don't deserve a 3\% contribution. Despite their agreement about excluding some services such as dentures and cosmetic surgery, most of them wanted chronic dialysis be included. A few participants agreed that out of country referrals for rare conditions should not be included as it contradicts the intention of health insurance to ensure access to basic health services for all citizens. One health professional supported this idea:

"I do agree on the services excluded from the benefit package, because these disease conditions can consume a large amount of the budget for few patients that would have been used to save more lives. It is rational first to focus on conditions that affect a majority of the people (Male 33 years, Health professional)".

\section{Quality of health services}

Most participants rated the quality of health service in public health facilities as very poor and lower as compared to private health facilities. Almost all participants revealed their dissatisfaction with the current services which are characterized by a chronic shortage of medications and diagnostic supplies. Thus, all participants suggested current health services must be improved prior to implementation of the SHI. This was illustrated by one participant:

"The current quality of health services is not optimal; there are challenges in receiving timely healthcare services. Again, we contribute to get services free of charge but from my experience medicines are frequently out of stock in public facilities and that means we will be forced to purchase them privately, as the private health facilities are not part of the scheme. It is frustrating if you paid and get nothing. It is better to improve the quality and availability of services prior to implementation, otherwise it might fail and it ultimately erodes public trust and will have unexpected repercussions (Male, 27 years, Health professional)". 


\section{Family members' eligibility}

Children above 18 years are not entitled to their parents' health insurance benefits. The FGD participants were not happy with this age limit as it does not consider the economic situation of the child. Eligibility should not be based on age but individual income. In Ethiopia, most children of 18 years are the 11th or 12th grade, and some may go on to post-secondary education. Thus, coverage under their parents' benefits should continue until approximately 23 years. One participant stressed that:

"If the scheme excludes my family member above 18 years, I don't support this program. This doesn't consider society's real situation, I mean the chance of getting work is low and even at this age most of them are high school students. So, it should not only consider age but also it should consider level of income. Or if the government decided to exclude above 18 years, there should be a means to create work for all citizens in that category (Male, 33 years, Health professional)".

\section{Discussion}

This study examined public servants' preference of healthcare financing, WTP and factors affecting their WTP for the nationally proposed SHI scheme. A majority was in favor of a publicly funded program and was willing to pay an amount similar to that proposed by the government. Participants raised concerns about which health services would be funded, the quality and availability of health services, and age limits on coverage of dependents.

Understanding the preferences of civil servants' healthcare financing options is important to estimate insurance uptake rate and implement a SHI scheme. Close to $90 \%$ of the respondents in the present study showed agreement on the need for SHI. This is relatively higher compared to previous studies in Ethiopia and elsewhere $[20,26-30]$. The difference might be due to difference in study locations, time, awareness about the importance of social health insurance or due to increasing health care costs. This higher level of agreement on SHI has important health policy implication in that a majority of public servants would accept the envisaged healthcare financing option provided that some changes in the policy packages would be made.

The current survey revealed that the overall estimated mean WTP for SHI was 3.6\% of respondents' monthly salary, which is more than the premium currently proposed by the government [18]. It is, however, comparable to what was documented by a previous study conducted in Southern Ethiopia but higher than reports in Addis
Ababa, the capital city [29, 31]. In contrast, most of our focus group discussants agreed to contribute about $2 \%$. The differences among FGD and our survey could be attributed to the approaches used to illicit their WTP. During the FGD, participants were presented with a fixed 3\% premium, the true contribution planned for the national SHI [18]. For the survey bid process, a number of different starting contributions were used and respondents were given hypothetical health insurance options. Evidence suggests people tend to demand low cost if they know the market values of that service [24].

This study found that age, educational status and household income were significantly associated with respondents' WTP. Older age was associated with willingness to pay less, while respondents with higher household income were willing to pay more for SHI. This was in line with other studies conducted in Ethiopia, Uganda and Iran [20, 26, 32]. But findings were contrary to other studies which indicated that elderly people who had a higher risk of illness were willing to pay more $[23,27,33]$. This might be due to differences in economic status among elderly population across countries during retirement. Therefore finding ways to increase the income of public servants may positively increase their WTP.

It is interesting to note also that contrary to previous studies [20,26, 27, 29, 32], in the present study more educated respondents showed willingness to pay less for SHI. This difference is due to the fact that our study population constituted health professionals who are largely getting healthcare free of charge, and hence contributing money, even if small amount, might be unacceptable to them.

Many other factors were indicated to affect WTP from the qualitative findings. The amount of premium and insurance benefit packages were among the most frequently raised issues during the discussion. Most participants revealed that about $2 \%$ is reasonable for the benefit package outlined in the current SHI policy but expressed willingness to contribute $3 \%$ provided the benefit packages would be revised to include some other services such as kidney dialysis. But few participants strongly opposed the inclusion of expensive services such as dialysis fearing that covering such services would drain the fund thereby compromising universal health coverage.

Quality of health services in public health facilities was an important issue in the focus groups. The majority of the participants were not satisfied with the availability and quality of health services in public facilities. They suggested that increasing the number of health professionals, improving medications and equipment supply, and bringing health services closer 
to the community would increase the acceptability of SHI. It is also important to note that implementation of SHI by itself could lead to increased patient load and further aggravate supply problems and affect the quality of health services [34-37]. This is an additional concern for policy makers to consider for the successful implementation of the SHI scheme.

Focus group discussants had concerns about ending benefits when a dependent turned 18 years old as per the recommendation of the current SHI policy [18]. All participants strongly contended that eligibility should not be based on age alone, but also on their capacity to generate income. Hence, further review of the plan and consultation with public servants is warranted before implementing $\mathrm{SHI}$.

\section{Conclusion}

The majority of participants in the studied area preferred SHI as their main approach to healthcare financing. Their mean WTP was $3.6 \%$ of their monthly salary, which is higher that the premium set by the government. This high acceptance rate and WTP has an important policy implication for the successful implementation of the scheme. Even though focus group discussants indicated a lower WTP, most discussants agreed to contribute more provided services are improved. Further dialogue with public servants is essential for successful uptake of the program.

\section{Additional files}

Additional file 1. English version questionnaire.

Additional file 2. Focus group pre-discussion survey.

Additional file 3. Focus group discussion guide.

Additional file 4. Hypothetical health care financing scenarios.

\section{Abbreviations}

DBDC: double bound dichotomous choice; FGD: focus group discussion; MOH: Ministry of Health; OOP: out of pocket; SHI: social health insurance; USAID: United States Agency for International Development; WHO: World Health Organization; WTP: willingness to pay.

\section{Authors' contributions}

MTG designed the study, supervised the data collection, did the analysis and drafted the manuscript; GBG, MEH and TGF involved in the design and conduct of the study. All authors read and approved the final manuscript.

\section{Author details}

${ }^{1}$ School of Pharmacy, College of Health Sciences, Mekelle University, Mekelle, Ethiopia. ${ }^{2}$ School of Pharmacy, College of Health Sciences, Addis Ababa University, Addis Ababa, Ethiopia. ${ }^{3}$ Leslie Dan Faculty of Pharmacy, University of Toronto, Toronto, Canada.

\section{Acknowledgements}

The authors would like to acknowledge Addis Ababa University for funding the project. We are also grateful to all institutions and study participants for their support to provide us relevant inputs for the accomplishment of the study.

\section{Competing interests}

The authors declare that they have no competing interests.

\section{Availability of data and materials}

All datasets from which we derived our conclusion is deposited in SPSS software in the hands of the first author. However, due to confidentiality issues, the raw data will not be shared.

\section{Consent to publish}

Not applicable.

\section{Ethics approval and consent to participate}

The study was conducted after ethical approval from the Ethics Review Board of the School of Pharmacy, Addis Ababa University. An official support letter was granted by the Tigray Regional Health and Education Bureaus to conduct the study. In addition, the study was conducted after securing an informed verbal consent from all participants.

\section{Funding}

Graduate Program of Addis Ababa University.

\section{Publisher's Note}

Springer Nature remains neutral with regard to jurisdictional claims in published maps and institutional affiliations.

Received: 4 October 2018 Accepted: 8 January 2019

Published online: 15 January 2019

\section{References}

1. Bump J, Cashin C, Chalkidou K, et al. Implementing pro-poor universal health coverage. Lancet Global Health. 2016;4(1):e14-6.

2. Averill C, Marriott A. Universal health coverage: why health insurance schemes are leaving the poor behind. Oxford: Oxfam International; 2013.

3. Maeda A, Araujo E, Cashin C, Harris J, Ikegami N, Reich MR. Universal health coverage for inclusive and sustainable development: a synthesis of 11 country case studies. Washington: World Bank Publications; 2014.

4. Rancic N, Jakovljevic MM. Long term health spending alongside population aging in N-11 emerging nations. East Eur Bus Econ J. 2016;2(1):2-6.

5. Mazumdar S, Guruswamy M. Demand and willingness to pay for healthcare in rural West Bengal. Social Change. 2009;39(4):568-85.

6. Jakovljevic M, Getzen TE. Growth of global health spending share in low and middle income countries. Front Pharmacol. 2016;7:21.

7. Dieleman J, Campbell M, Chapin A, Eldrenkamp E, Fan VY, Haakenstad A, Kates J, Liu Y, Matyasz T, Micah A, Reynolds A. Evolution and patterns of global health financing 1995-2014: development assistance for health, and government, prepaid private, and out-of-pocket health spending in 184 countries. Lancet. 2017;389(10083):1981-2004.

8. Dieleman JL, Campbell M, Chapin A, Eldrenkamp E, Fan VY, Haakenstad A, Kates J, Li Z, Matyasz T, Micah A, Reynolds A. Future and potential spending on health 2015-2040: development assistance for health, and government, prepaid private, and out-of-pocket health spending in 184 countries. Lancet. 2017:389(10083):2005-30.

9. Odeyemi IA. Community-based health insurance programs and the national health insurance scheme of Nigeria: challenges to uptake and integration. Int J Equity Health. 2014;13(1):20.

10. World Health Organization. Social health insurance: Sustainable health financing, universal coverage and social health insurance. Geneva: Switzerland; 2005.

11. Carrin G, James C. Social health insurance: key factors affecting the transition towards universal coverage. Int Soc Security Rev. 2005;58:45-64.

12. World Health Organization. The abuja declaration: 10 years on. Geneva: World Health Organization; 2011.

13. World Health Organization. Health system financing profile in Ethiopia. Geneva: World Health Organization; 2013. 
14. MOH. Ethiopia's Fifth National Health Accounts, 2010/2011. Addis Ababa: Federal Ministry of Health; 2014.

15. $\mathrm{MOH}$. The Ethiopian health care financing strategy. Addis Ababa: $\mathbf{M O H}$; 1998

16. Health Care Financing Reform in Ethiopia: Improving Quality and Equity. http://www.hfgproject.org/health-care-financing-reform-ethiopia-impro ving-quality-equity/. Accessed 10 Jun 2017.

17. Purvis $G$, Alebachew A, Feleke W. Ethiopia health sector financing reform midterm project evaluation. Washington: USAID; 2011.

18. Council of Ministers. Social Health Insurance Regulation No. 271/2012. Addis Ababa: Federal NegaritGazeta of the Federal Democratic Republic of Ethiopia. 2012

19. Haile M, Ololo S, Megersa B. Willingness to join community-based health insurance among rural households of Debub Bench District, Bench Maji Zone, Southwest Ethiopia. BMC Public Health. 2014;14(1):591.

20. Habtewold YW. Preference for health care financing options and willingness to pay for compulsory health insurance among government employees in Ethiopia. Umeå: Umeå International School of Public Health; 2009

21. Mnally LP. Determinants of health insurance participation among informal sector workers in rural Tanzania. (Doctoral dissertation, Sokoine University of Agriculture) 2013.

22. Bateman IJ, Carson RT, Day B, et al. Economic valuation with stated preference techniques: a manual. 2002.

23. Entele BR, Emodi NV. Health insurance technology in Ethiopia: willingness to pay and its implication for health care financing. Am J Public Health Res. 2016:4(3):98-106

24. Venkatachalam L. The contingent valuation method: a review. Environ Impact Assess Rev. 2004;24(1):89-124.

25. Lopez-Feldman A. Introduction to contingent valuation using Stata (MPRA Paper No. 41018). 2012.

26. Muheki CW. Willingness to pay for social health insurance: a case study of Kampala (Uganda) (Doctoral Dissertation, University of Cape Town). 1998.
27. Salameh AM, Juni MH, Hayati KS. Willingness to pay for social health insurance among academic staff of a public University in Malaysia. Int J Public Health Clin Sci. 2015;2(5):21-32.

28. Byabashaija AA. The knowledge and views of teachers in government educational institutions in Kampala District on the proposed Social Health Insurance Scheme in Uganda. Health Policy Dev. 2009;7(1):1-9.

29. Agago TA, Woldie M, Ololo S. Willingness to join and pay for the newly proposed social health insurance among teachers in Wolaita Sodo town, south Ethiopia. Ethiop J Health Sci. 2014;24(3):195-202.

30. Defar A, Seyum A, Gelibo T, Getachew T. Willingness to pay for social health insurance and associated factors among health sector employees in Addis Ababa, Ethiopia. In: MOH 18th Annual Review Meeting. MOH; 2016.

31. Obse A, Ryan M, Heidenreich S, Normand C, Hailemariam D. Eliciting preferences for social health insurance in Ethiopia: a discrete choice experiment. Health Policy Plan. 2016;31(10):1423-32.

32. Nosratnejad S, Rashidian A, Mehrara M, Sari AA, Mahdavi G, Moeini M. Willingness to pay for social health insurance in Iran. Global J Health Sci. 2014;6(5):154.

33. Adams R, Chou YJ, Pu C. Willingness to participate and Pay for a proposed national health insurance in St. Vincent and the Grenadines: a cross sectional contingent valuation approach. BMC Health Services Res. 2015;15(1):148

34. Wright J. Essential package of health services country snapshot. 2015

35. $\mathrm{MOH}$. Background paper on introducing social and community based health insurance schemes in Ethiopia. Addis Ababa: MOH; 2006.

36. USAID. Ethiopian health sector financing reform midterm project evaluation. Contract No. 11-01-598. Washington: USAID; 2011

37. Dibaba A, Ababor S, Assefa Y. Improving health care financing in Ethiopia (SURE policy brief). Addis Ababa: Ethiopian Public Health Institute; 2014.

Ready to submit your research? Choose BMC and benefit from

- fast, convenient online submission

- thorough peer review by experienced researchers in your field

- rapid publication on acceptance

- support for research data, including large and complex data types

- gold Open Access which fosters wider collaboration and increased citations

- maximum visibility for your research: over $100 \mathrm{M}$ website views per year

At $\mathrm{BMC}$, research is always in progress.

Learn more biomedcentral.com/submissions 